\title{
Review
}

\section{Human dignity}

\author{
George Kateb \\ Belknap Press, Cambridge MA, 2011, xvi + 238pp., £16.95/\$22.95; \\ ISBN: 978-0674048379
}

Contemporary Political Theory (2012) 11, e8-e10. doi:10.1057/cpt.2011.24

In Human Dignity, George Kateb seeks to develop a conception of dignity grounded in the achieved stature of the species but used to protect the entitled status of each of its members - that is capable of serving as the foundation for human rights. This is at least the nominal aim of this wide ranging and often contemplative book, which explores the development of rights in US constitutional jurisprudence and international politics, but along the way tilts at such recent phenomena as Bush administration anti-terrorism policies, the 'despotism of superficiality' in social media like Twitter and Facebook (p. 207), 'naturalist reductions' of human agency like evolutionary psychology and neuroscience that 'unnecessarily tarnish human dignity by taking away commendable uniqueness from it' (p. 128), and environmentalist ontologies that situate humanity within the natural world rather than acknowledging human uniqueness. Throughout, dignity and a passionate commitment to a somewhat underspecified set of human rights play a unifying thematic role, with Kateb's Emersonian individualism providing a critical undercurrent. Largely eschewing footnotes or other direct forms of scholarly reference, and simultaneously engaging events of the present as well as timeless historical ideas, the book reads more like an intellectual memoir than a sustained argument or interpretive text. Readers looking for a wholly new foundation upon which to construct rights theories may come away disappointed, but most will likely find Kateb's ability to move effortlessly between current affairs and historical arts and letters to be edifying and inspiring, as if the life of the mind is necessarily that of the social critic.

The book's core claim is easily summarized: rights are justified by the unique qualities and capacities of humanity and its historical achievements, which lend the species both a dignity that cannot be found elsewhere in nature and a set of responsibilities to go along with it. Rights, in turn, ought to be used to protect individual human status, wherein each of us strives against manifold obstacles to lead a dignified life. Others have likewise sought to ground human rights

(C) 2012 Macmillan Publishers Ltd. 1470-8914 Contemporary Political Theory Vol. 11, 4, e8-e10 www.palgrave-journals.com/cpt/ 
in dignity, and although Kateb does not directly address other foundational approaches or contrast his own view with others taking a similar view, his intellectual debts are evident enough. Of his Kantianism, for example, he acknowledges that a conception of dignity 'easily produces the idea that no one should be a mere means to some higher end' (p. 163), and his critique of paternalism, or treating 'people as if they were children that can never grow up' (p. 111), clearly invokes J.S. Mill. While he takes some pain in defending his view against three critical perspectives in egocentrism, ethical individualism and virtue approaches, this philosophical defense of dignity as a core value or of rights as instrumental to advancing it is less impressive than the rich and integrative discussion in which it is embedded. As he describes, dignity should inform how we organize our personal lives as well as our societies, and rights comprise only a small aspect of this project, even if they enable those functions and aspirations that Kateb's exploration highlights.

Notable in Kateb's account of dignity is his human exceptionalism, which draws a sharp line between humanity and the rest of the natural world. Claiming that 'the defense of human rights needs a philosophical anthropology that explores human uniqueness' (p. 122), he locates this uniqueness in 'three indispensable functions' of understanding, appreciating and keeping the record of nature, which together 'constitute stewardship of nature' (p. 114). Elsewhere he suggests that it is the human capacity for language and self-consciousness that warrants this division, writing that 'only humanity can speak about the rest of nature or for it' (p. 117). As he describes, this stewardship imperative gives humans the opportunity to achieve the stature that is essential for the dignity of the entire species. Caring for other species, and saving them from the threat of extinction caused by anthropogenic environmental degradation, requires magnanimity, which he calls 'the one principal virtue of human stature' (p. 142). But the record of human-caused extinctions suggests that humanity in its relationship to non-human nature has not been magnanimous, nor has it been marked by the 'great achievements' upon which Kateb elsewhere grounds human stature (p. 8). Rather, we humans have abjectly failed to be 'selfless enough to be able to treat the non-human disinterestedly or reverently, in distinction from the brutality that human beings inflict on one another' (p. 115), often mistreating non-humans precisely because we regard them as brutes, categorically different from humans in and thus unworthy of moral standing. Such failure would therefore seem to cast doubt upon human stature, which Kateb suggests is achievable and indeed historially achieved, despite massive and continuing failures in this obligation of stewardship. If human stature is to be 'redeemed' from its record of atrocities against our fellow humans by good environmental stewardship, that stature must be viewed as an aspiration for human stature rather than as an achievement conferring that stature, as he elsewhere suggests. 
Kateb seems aware of the controversy surrounding this ontology, which opposes most environmentalist thought since Aldo Leopold's $A$ Sand County Almanac (1949), which implores its readers to regard humans as 'plain citizens' of the natural world rather than conceptually separating themselves from it. In asserting that humanity 'possesses valuable, commendable uniqueness or distinctiveness that is unlike the uniqueness of any other species' and 'is not only natural, whereas all other species are only natural' (p. 5), Kateb invites rebuke from ecological critics on both empirical and normative grounds. He characterizes the humans-in-nature view that he rejects as worrying 'that human hubris, which does not need encouragement, will justify the disregard of the interests of nature' (p. 142), since elevating humans above nature would also seem to entail elevating their interests above those of non-humans, diminishing or disregarding altogether the latter, but offers little in reply to this worry. Although he calls for an end to 'the human prejudice that animals and the rest of nature exist solely for human use' (p. 116), mentions in passing that 'we could even speak of animal rights' (p. 117), and declares his aim of 'redirecting the idea of human stature toward the stewardship of nature', he continues to insist that 'reducing human beings to animality is not the way to ask us to raise ourselves to a proper height so that we may serve as stewards of nature' (p. 152). Surely, the stewardship ethic that Kateb seeks to instill could be well served by raising the status of non-humans, perhaps even recognizing some analogous form of dignity within the natural world, rather than reducing the status of humans to some presumably undignified animality. Indeed, perhaps human dignity could best be advanced by recognizing the equal dignity of others, or appreciating the uniqueness that exists beyond the human world as well as that within it. Regardless, Kateb's exploration of the role of such dignity, whether as a foundation for human rights or as a value to be expressed through egalitarian democracy or purposeful living, offers readers an enchanting vision of how persons or societies may aspire toward an Emersonian 'infinitude' in public and private life, and an impassioned defense of the social and political conditions that enable it.

Steve Vanderheiden

University of Colorado at Boulder

Boulder CO, USA 